07,14

\title{
Полимерные пьезоэлементы на основе пористых пленок поливинилиденфторида и контактных электродных слоев полианилина
}

\author{
(С) Г.К. Ельяшевич, И.С. Курындин, Е.Ю. Розова, Н.Н. Сапрыкина \\ Институт высокомолекулярных соединений РАН, \\ Санкт-Петербург, Россия \\ E-mail: elya@hq.macro.ru
}

Поступила в Редакцию 5 ноября 2019 г.

В окончательной редакции 5 ноября 2019 г.

Принята к публикации 5 ноября 2019 г.

Разработан метод получения новых гибридных пьезоактивных систем путем последовательной послойной окислительной полимеризации анилина in situ на пористых пленках поливинилиденфторида, сформованных в процессе, основанном на экструзии расплава. Методом ИК-спектроскопии установлено, что полианилин образуется в проводящей форме (эмеральдиновой соли). Показано, что образцы, содержащие два слоя полианилина, имеют более высокую электропроводность, чем при однослойном нанесении, и ее величина возрастает со степенью ориентации подложки. Результаты исследований методом СЭМ подтвердили, что этот эффект связан с повышением однородности и упорядоченности структуры проводящего слоя. Показано, что гибридные системы имеют более высокие прочность, модуль упругости и удлинение при разрыве, чем подложки. Электро- и пьезоактивные свойства образцов изучены методами циклической вольтамперометрии и измерениями пьезомодуля с использованием слоя полианилина в качестве контактного электродного материала. Определены значения пьезоконстант в зависимости от направления приложения нагрузки.

Ключевые слова:поливинилиденфторид, полианилин, пористые пленки, электропроводность, пьезомодуль.

DOI: 10.21883/FTT.2020.03.49018.623

\section{1. Введение}

Электроактивные полимеры относятся к числу наиболее интересных соединений, используемых в качестве интеллектуальных материалов различного применения, таких как датчики, исполнительные устройства, энергетические преобразователи, а также в качестве биоматериалов в области биомедицины [1]. Среди немногих полимеров, обладающих пьезо-, пироэлектрическими или сегнетоэлектрическими свойствами, поливинилиденфторид (ПВДФ) и его сополимеры обладают наилучшими универсальными электроактивными свойствами, что делает их перспективными для использования в устройствах различного назначения [2-5]. Поливинилиденфторид является важнейшим полимерным пьезоэлектриком, т.к. он, помимо пьезосвойств, обладает химической инертностью и высокими механическими характеристиками.

Задача разработки полимерных пленочных пьезоэлементов на основе ПВДФ является одной из наиболее актуальных в области химии, физики и технологии полимерных материалов в связи с тем, что, будучи полимерным пьезоэлектриком, он обладает рядом уникальных свойств, которых нет у традиционных неорганических пьезоэлектриков типа кварца или титаната бария, применяемых, в частности, в гидроакустических приборах. К преимуществам полимерных пьезоэлектриков относится технологичность их производства, воз- можность получения пьезоматериалов в виде тонких пленок, эластичность и низкая плотность, что делает пьезопленки ПВДФ незаменимыми при изготовлении многих устройств. Большое значение имеет тот факт, что полимерные пьезоэлементы могут относительно легко быть изготовлены в виде пленочных материалов без ограничения по максимальной площади поверхности.

ПВДФ - полиморфный полимер, он кристаллизуется с образованием ряда полиморфных модификаций, главным образом, в неполярной $\alpha$-форме и полярной $\beta$-форме. Его пьезосвойства связаны с возможностью формирования в его кристаллической структуре значительной доли кристаллитов пьезоактивной $\beta$-модификации [6-8]. Исследования в области разработки пьезоэлемпентов на основе ПВДФ направленны на увеличение содержания пьезоактивных полярных кристаллитов $\beta$-формы и формирование электродных слоев на поверхности пьезопленок. В настоящее время в качестве полимерных пьезопленок используются „гладкие“ непористые пленки ПВДФ и его сополимеров, получаемые экструзией их расплава или отливом из растворов с последующей ориентацией, металлизацией и поляризацией в электрическом поле высокого напряжения. Существенным затруднением при получении пьезоэлементов на основе ПВДФ с токопроводящими электродными слоями является низкая адгезия „гладких“ пленок к электродным материалам, включая большинство полимерных и низкомолекулярных покрытий. 
В данной работе для получения пьезоэлементов использовали пористые пленки ПВДФ, сформованные методом, основанным на экструзии расплава полимера с последующими стадиями отжига, одноосного растяжения и термофиксации [9-11]. Пористая структура этих пленок характеризуется наличием сквозных каналов, которые образуются по перколяционному механизму на стадии порообразования в процессе роста общей пористости и достижении ею значений, соответствующих порогу перколяции $(23-25 \%)[11,12]$. Особенностью этих пленок является рельефный характер их поверхности, который формируется вследствие „выброса“напряжения при образовании в пленках сквозных пор. Именно высокоразвитая рельефная поверхность обеспечивает нанесенным покрытиям сцепление с пленкой, которое реализуется по механизму механической адгезии и не зависит от природы нанесенного компонента. Разработанный метод $[13,14]$ позволил получить пористые пленки полиолефинов (ПЭ, ПП), содержащие сквозные каналы, и гибридные материалы на их основе, демонстрирующие высокую адгезию между подложкой и нанесенными на нее активными компонентами различной природы [15-20].

Существующие в настоящий момент методики формирования электродов на поверхности пленок относятся к затратным и/или трудоемким, малопроизводительным процессам, которые имеют ограничения при необходимости получать пленки большого размера. Использование электропроводящих полимеров в качестве электродного материала открывает новые возможности для получения прочных и эластичных полимерных пьезоэлементов нового типа. Однако известные методики нанесения слоев электропроводящих полимеров на поверхность пьезопленок ПВДФ инициируют структурные изменения, которые непредсказуемо сказываются на пьезоэффекте, вызывают появление дефектов и ухудшение механических свойств (потерю эластичности) образцов, требуют использования большого количества дополнительных реагентов, а также накладывают ограничения на размеры образцов при их обработке облучением [21-26]. Методы электрохимической обработки отрицательно влияют на электропроводность слоев из-за перегрева образца, вызывают нарушение геометрической формы пленки и имеют пониженную технологичность.

Задачами настоящего исследования были разработка эффективного метода формирования слоев проводящего полимера - полианилина - (ПАНИ) в качестве электродов на пьезопленках ПВДФ, определение структуры и свойств полученных гибридных образцов ПВДФ/ПАНИ и изучение влияния степени ориентации подложки на эти свойства, а также проведение поляризации пьезопленок ПВДФ/ПАНИ и измерение их пьезомодуля. Решение этих задач имело целью получение полностью полимерных пьезоэлементов на основе пленок ПВДФ, обладающих высоким содержанием пьезоактивной кристаллической $\beta$-формы и снабженных электропроводящим полимерным электродным слоем.

\section{2. Объекты и методы исследования}

В данной работе исходные пленки ПВДФ получали экструзией расплава полимера Kynar-720 (Atofina Chemicals Inc., США) с молекулярной массой $1.9 \cdot 10^{5}$ и температурой плавления $170^{\circ} \mathrm{C}[11]$.

Общую пористость пленок ПВДФ определяли гравиметрическим методом и рассчитывали по формуле

$$
P=\left[\left(\rho-\rho_{\Pi}\right) / \rho\right] \cdot 100 \%,
$$

где $\rho-$ плотность монолитной пленки ПВДФ $\left(1.78 \mathrm{~g} / \mathrm{cm}^{3}\right), \rho_{\text {п }}-$ плотность пористой пленки, определенная по взвешиванию.

Проницаемость пористых подложек для жидкости измеряли по скорости протекания этанола под давлением $0.5 \mathrm{MPa}$ через образец, помещенный в фильтрационную ячейку.

Удельную поверхность и размеры пор определяли методом термической десорбции азота на приборе „Сорбтометр М“ (Новосибирск, Россия).

Электропроводящий компонент - полианилин формировали непосредственно на поверхности пористых пленок ПВДФ методом окислительной полимеризации мономера (анилина) in situ. Содержание проводящего полимера $(x)$ в полученных образцах ПВДФ/ПАНИ рассчитывали по формуле

$$
x=\Delta W /\left(W_{\text {ПвдФ }}+\Delta W_{\text {пр }}\right) \cdot 100 \%,
$$

где $W_{\text {ПвдФ }}-$ масса исходной пористой пленки ПВДФ, $\Delta W_{\text {пр }}$ - разность масс образца ПВДФ/ПАНИ и подложки ПВДФ.

ИК-Фурье спектры пленок снимали на спектрометре „Vertex70“6 („Bruker“, США).

Электронно-микроскопические (СЭМ) картины поверхности пористых пленок и образцов ПВДФ/ПАНИ были получены на сканирующем микроскопе SUPRA-55VP (ZIESS, Германия).

Смачиваемость поверхности пленок определяли методом сидячей капли на приборе DSA30 (KRUSS, Германия).

Электрическую проводимость образцов измеряли с использованием потенциостата Р-30 (Элинс, Черноголовка, Россия) стандартным четырехточечным методом Ван-дер-Пау в постоянном токе при комнатной температуре и рассчитывали по формуле:

$$
\sigma=(\ln 2 \cdot I) /(\pi \cdot U \cdot \delta)
$$

где $\sigma$ - проводимость, $I-$ сила тока в цепи, $U-$ разность потенциалов на образце, $\delta$ - толщина пленки.

Измерения методом циклической вольтамперометрии также проводили с помощью потенциостата Р-30 в трехэлектродной ячейке в среде $1 \mathrm{M}$ раствора $\mathrm{HCl}$.

Поляризацию пленок ПВДФ осуществляли методом высоковольтной контактной термополяризации в постоянном электрическом поле с напряженностью 

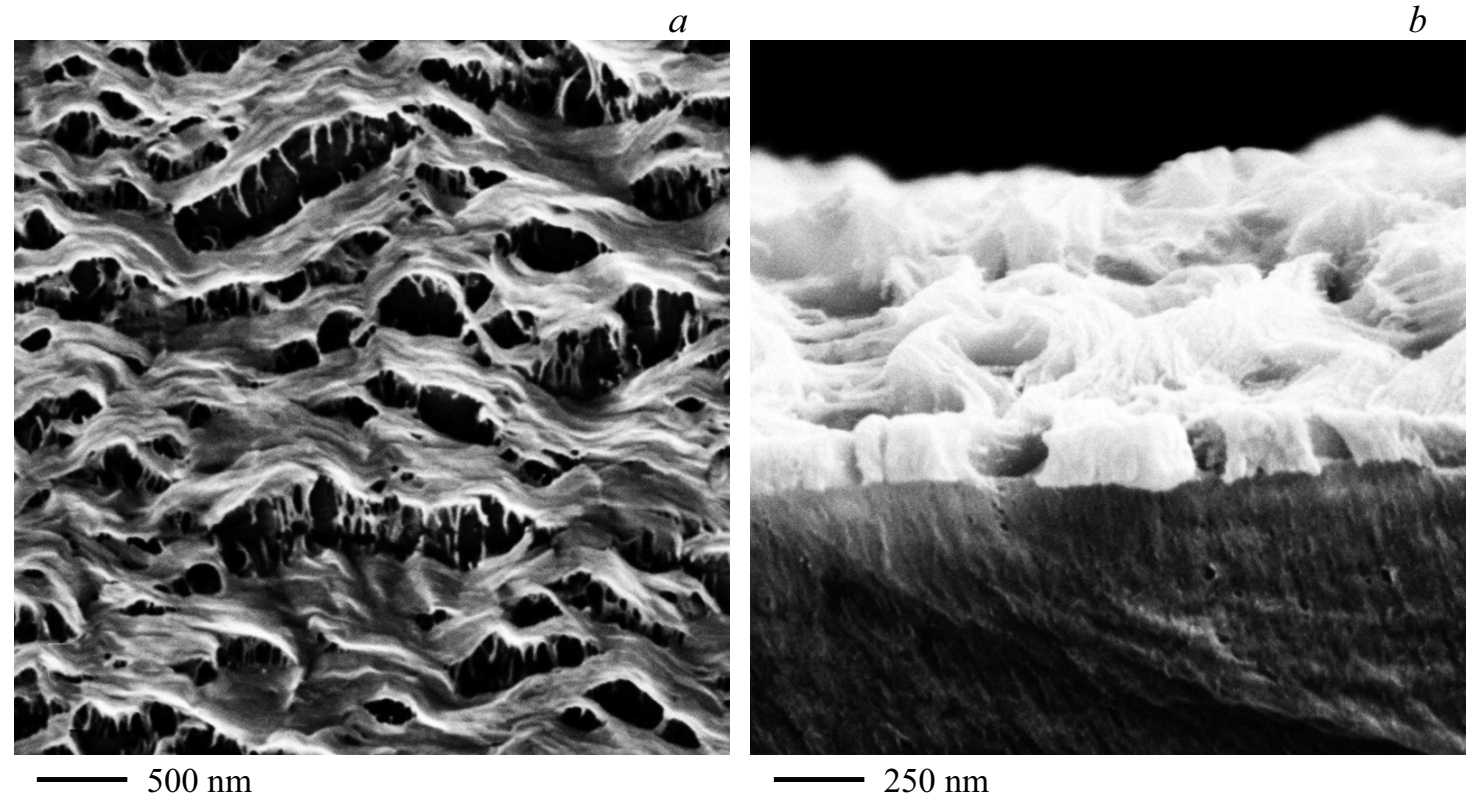

Рис. 1. СЭМ-картины поверхности $(a)$ и поперечного сечения $(b)$ пористой пленки ПВДФ, сформованной при $\lambda=103$.

80-90 V/ $\mu$ m при температуре $90^{\circ} \mathrm{C}$ в течение $1 \mathrm{~h}$, после чего пленку охлаждали в выключенном термостате при включенном электрическом поле. Эти условия поляризации были определены экспериментально как оптимальные, а именно, позволяющие получить наиболее высокополяризованные образцы и избежать электрического пробоя.

Пьезомодуль $d_{i j}$ измеряли статическим методом приложения растягивающего усилия вдоль и перпендикулярно направлению ориентации поляризованной пленки. С помощью потенциостата Р-30 („Элинс“, Черноголовка, Россия) измеряли разность потенциалов, возникающую на контактных электродах (слоях проводящего полимера) образца при его деформации. Пьезомодуль $d_{i j}$ рассчитывали по формуле:

$$
d_{i j}=C \cdot \Delta U \cdot B /(A \cdot \Delta F),
$$

где $C=C_{x}+C_{0} ; \Delta U=U_{2}-U_{1} ; \Delta F=F_{2}-F_{1} ; C_{x}-$ емкость образца, $\mathrm{F} ; C_{0}$ - емкость образцового конденсатоpa $(1 \mu \mathrm{F}) ; A-$ площадь электродов, $\mathrm{cm}^{2} ; B-$ площадь поперечного сечения пленки, $\mathrm{cm}^{2} ; F-$ растягивающее усилие, $\mathrm{N} ; U$ - электрическое напряжение, $\mathrm{V} ; U_{1}$ и $U_{2}-$ электрическое напряжение при $F_{1}$ и $F_{2}$ соответственно.

Определение механических свойств пористых пленок ПВДФ и композиционных систем проводили на разрывной машине 2166 Р-5 („Точприбор“, Иваново, Россия). Прочность, модуль упругости и относительную деформацию при разрыве измеряли с помощью кривых напряжение-деформация, полученных при одноосном растяжении образцов размером $50 \times 5 \mathrm{~mm}$ со скоростью $50 \mathrm{~mm} / \mathrm{min}$. Прочность рассчитывали как максимальное (разрывное) усилие, отнесенное к начальному поперечному сечению образца. Модуль упругости определяли при деформации $\sim 0.5 \%$.

\section{3. Результаты и обсуждение}

Экструдированные пленки ПВДФ, полученные при кратностях фильерной вытяжки $\lambda=55,73$ и 103, были подвергнуты изометрическому отжигу при $168^{\circ} \mathrm{C}$ в течение $1 \mathrm{~h}$. Пористая структура пленок была сформирована в двухстадийном процессе одноосного растяжения при комнатной и повышенной $\left(100^{\circ} \mathrm{C}\right)$ температурах с варьируемой степенью „холодной“ вытяжки от 40 до $80 \%$ и фиксированной степенью горячей вытяжки 40\%. Степень ориентации пленок характеризовали суммарной кратностью вытяжки $\varepsilon$, равной произведению кратностей холодной и горячей вытяжек. Затем пористую структуру фиксировали выдержкой в изометрических условиях при $100^{\circ} \mathrm{C}$ в течение $1 \mathrm{~h}$ для предупреждения усадки образцов после снятия растягивающего напряжения. Измерения проницаемости пленок по протеканию жидкости (этанола) показали, что с ростом $\lambda$ она увеличивается в результате возрастания числа и размера пор (табл. 1).

Электронно-микроскопические картины пленок (рис. 1) показывают, что пористые пленки имеют рельефную, сильно развитую поверхность в форме чере-

Таблица 1. Характеристики пористых подложек ПВДФ

\begin{tabular}{l|c|c|c}
\hline Кратность фильерной вытяжки, $\lambda$ & 55 & 73 & 103 \\
\hline Толщина, $\mu \mathrm{m}$ & 27 & 21 & 15 \\
Общая пористость, \% & 27 & 28 & 29 \\
Удельная поверхность, $\mathrm{m}^{2} / \mathrm{g}$ & 28 & 30 & 37 \\
Проницаемость по скорости & 0.4 & 0.7 & 1.0 \\
протекания этанола, $l /\left(\mathrm{m}^{2} \cdot \mathrm{h} \cdot \mathrm{atm}\right)$ & & & \\
Средний размер пор, $\mathrm{nm}$ & 15 & 18 & 20
\end{tabular}




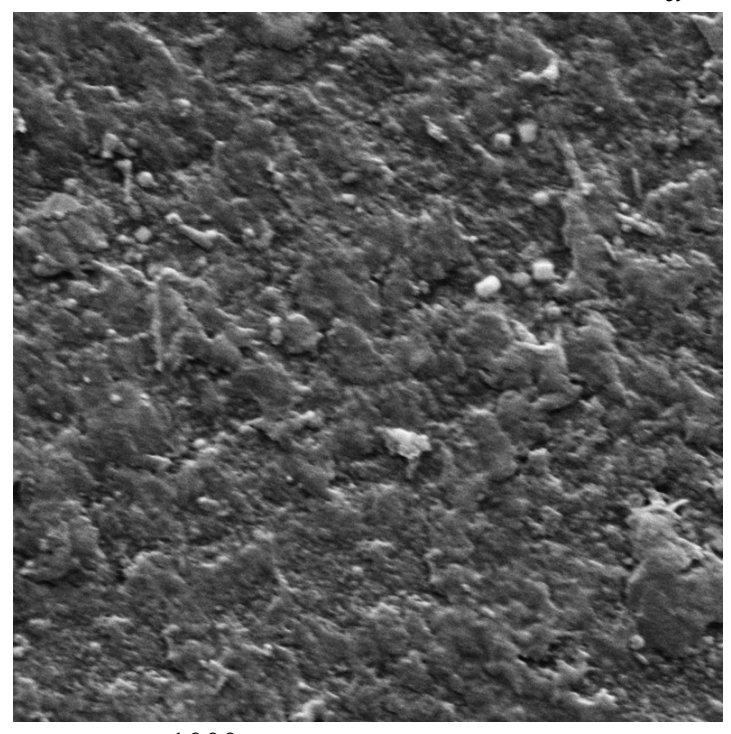

$1000 \mathrm{~nm}$

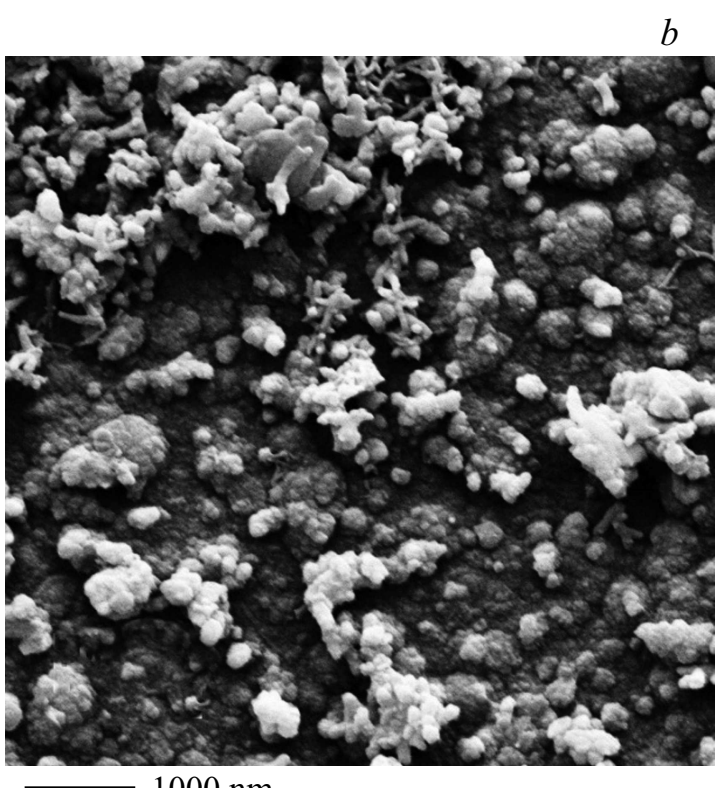

$1000 \mathrm{~nm}$

Рис. 2. СЭМ-картины поверхности образцов ПВДФ/ПАНИ: однократная $(a)$ и двукратная $(b)$ полимеризация.

дующихся гребнеобразных выступов высотой $1-2 \mu \mathrm{m}$, вытянутых перпендикулярно направлению ориентации пленки, и впадин, отражающей характер внутренней ламеллярной структуры образца на более высоком масштабном уровне. Масштаб рельефа поверхности возрастает с увеличением степени ориентации, что приводит к повышению величины удельной поверхности до нескольких десятков $\mathrm{m}^{2} / \mathrm{g}$ (табл. 1), в то время как для непористых (экструдированной и отожженной) пленок удельная поверхность имеет величину порядка $10^{-4} \mathrm{~m}^{2} / \mathrm{g}$.

Пористые пленки ПВДФ были использованы для формирования слоев электропроводящего полимера (ПАНИ) на их поверхности. Для синтеза ПАНИ готовили два раствора: $0.2 \mathrm{M}$ раствор гидрохлорида анилина в $1 \mathrm{M}$ водном растворе $\mathrm{HCl}$ и $0.25 \mathrm{M}$ раствор окислителя - пероксидисульфата аммония в воде. Растворы смешивали и помещали пористую пленку ПВДФ в полимеризационную смесь на $24 \mathrm{~h}$. Затем пленку ПВДФ/ПАНИ извлекали, промывали $0.1 \mathrm{M}$ раствором $\mathrm{HCl}$ и сушили на воздухе. Образующийся на пленке полимер имел изумрудно-зеленую окраску, что свидетельствовало о проводящей форме ПАНИ (эмеральдиновой соли). Для получения более плотного и однородного слоя ПАНИ была проведена повторная полимеризация анилина на поверхности уже сформированнного образца ПВДФ/ПАНИ помещением его в свежую полимеризационную смесь. Эта процедура приводила к существенному увеличению содержания ПАНИ в гибридной системе и повышению ее электропроводности (табл. 2). В полученных образцах слои ПАНИ формировались на обеих сторонах подложки ПВДФ. В табл. 2 видно также, что электропроводность образцов ПВДФ/ПАНИ возрастает с увеличением степени ориентации подложек. Достигнутые для ПВДФ/ПАНИ значения проводимости
Таблица 2. Характеристики образцов ПВДФ/ПАНИ

\begin{tabular}{c|c|c|c}
\hline$\lambda$ & $\begin{array}{c}\text { Толщина, } \\
\mu \mathrm{m}\end{array}$ & $\begin{array}{c}\text { Содержание } \\
\text { ПАНИ, } \%\end{array}$ & $\begin{array}{c}\text { Проводимость, } \\
\text { S/сm }\end{array}$ \\
\hline 55 & $27 / 28$ & $0.7 / 2.1$ & $0.4 / 0.6$ \\
73 & $21 / 22$ & $0.9 / 2.8$ & $0.5 / 0.8$ \\
103 & $15 / 16$ & $1.3 / 3.9$ & $0.7 / 1.1$
\end{tabular}

Примечание. В числителе приведены значения для образцов, полученных однократной полимеризацией ПАНИ, в знаменателе двукратной.

сопоставимы с известными данными для полимерных электропроводящих гибридных систем: например, для смесевых композиций ПВДФ/ПАНИ были получены значения $10^{-1}$ и $10^{-4} \mathrm{~S} / \mathrm{cm}$ в работах [27] и [28] соответственно.

Приведенные в табл. 2 значения проводимости характеризуют образцы ПВДФ/ПАНИ $(0.6,0.8$ и $1.1 \mathrm{~S} / \mathrm{cm})$, в которых доля проводящего компонента при двукратной полимеризации находится в интервале 2.1-3.9\%. Следовательно, расчет проводимости самого полианилина, обеспечивающего показатели для ПВДФ/ПАНИ, дает $28 \mathrm{~S} / \mathrm{cm}$. Отметим, что проводимость для порошка ПАНИ, полученного в тех же условиях, что и на пленках ПВДФ, и спрессованного в виде таблеток, т.е. для блочных неориентированных образцов, составила $22 \mathrm{~S} / \mathrm{cm}$, что несколько ниже значений для ориентированных образцов ПВДФ/ПАНИ. Увеличение ориентации подложки в нашей серии образцов способствует формированию ориентированной структуры слоя ПАНИ и, как следствие, возрастанию его проводимости, что наблюдалось нами ранее для слоев ПАНИ на пористой пленке полиэтилена [29]. Достигнутые величины 


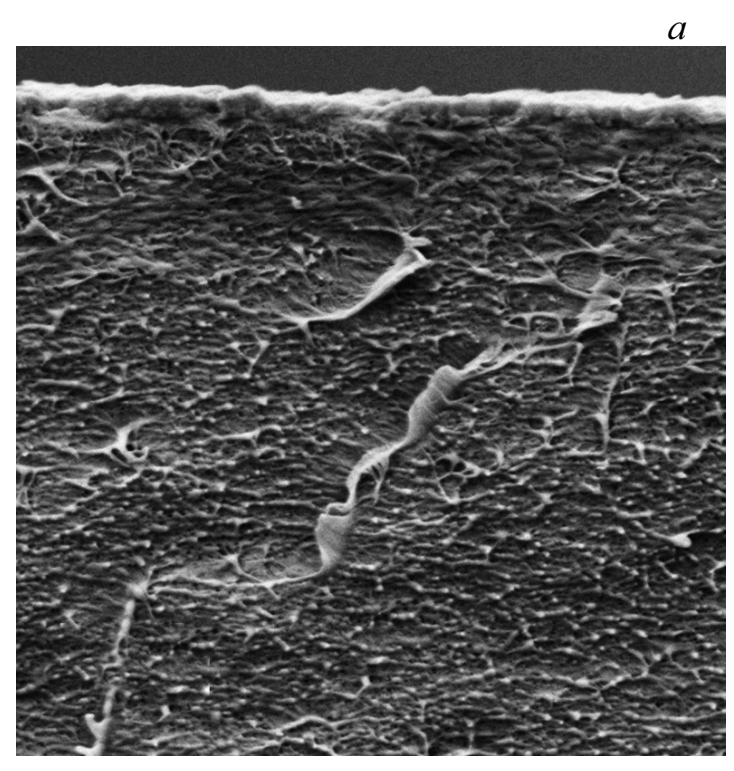

$1000 \mathrm{~nm}$

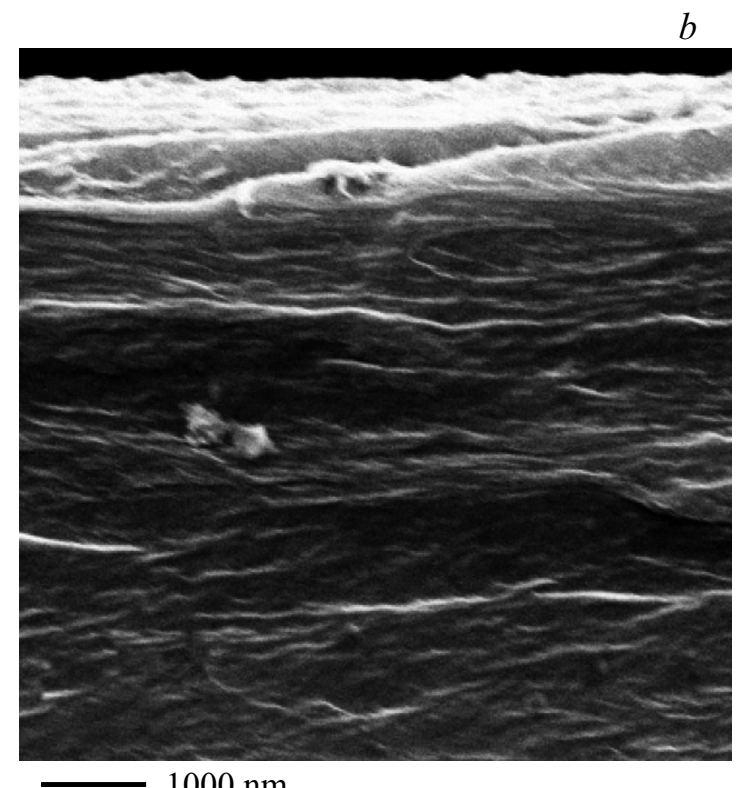

$1000 \mathrm{~nm}$

Рис. 3. СЭМ-картины поперечного сечения образцов ПВДФ/ПАНИ: однократная $(a)$ и двукратная $(b)$ полимеризация.

проводимости для ПАНИ являются одними из самым высоких для этого полимера и существенно превышают проводимость образцов ПАНИ (4-5 S/cm), полученных с использованием того же окислителя (персульфат аммония), приведенные, например, в работе [30].

Морфология слоев ПАНИ на пленках ПВДФ была исследована методом СЭМ (рис. 2). На рисунке видно, что уже первый слой ПАНИ практически полностью покрывает поверхность подложки ПВДФ, однако, он достаточно тонкий и содержит дефекты, о чем свидетельствует наблюдаемый разброс значений проводимости по поверхности. В то же время картина поверхности образца после повторной полимеризации демонстрирует плотный однородный слой ПАНИ, структура которого имеет типичный для ПАНИ глобулярный характер.

При сравнении СЭМ-снимков поперечного сечения подложки и образцов ПВДФ/ПАНИ хорошо видно заполнение пористой структуры пленки проводящим полимером (рис. 3).

Изменение характера структуры слоя при повторной полимеризации подтверждаются измерениями проводимости образцов в зависимости от степени ориентации подложки на стадии „холодной вытяжки“. На рис. 4 видно, что образцы, полученные однократной полимеризацией, имеют более низкую проводимость, которая лимитируется недостаточной однородностью и плотностью слоя ПАНИ. В то же время для образцов, сформированных и однократной, и двукратной полимеризацией анилина, наблюдается повышение проводимости с увеличением степени ориентации подложки, связанное с возрастанием пористости и размера пор и соответствующим повышением содержания ПАНИ (табл. 2), а также с совершенствованием структуры слоя ПАНИ.
Химическая структура систем ПАНИ/ПВДФ была изучена методом ИК-спектроскопии (рис. 5). Были получены спектры исходной подложки ПВДФ, образца ПАНИ/ПВДФ и спектр, представляющий собой разность данных спектров. В области 1570 и $1480 \mathrm{~cm}^{-1}$ наблюдаются полосы поглощения, соответствующие валентным колебаниям в бензольных и хиноидных кольцах ПАНИ, соответственно. Присутствие в структуре ПАНИ как бензольных, так и хиноидных колец свидетельствует об образовании проводящей формы ПАНИ со средней степенью окисления - эмеральдиновой соли. Полоса поглощения в области $1240 \mathrm{~cm}^{-1}$ соответствует валентным колебаниям протонированной $\mathrm{C}-\mathrm{N}^{+}$-структуры. Таким

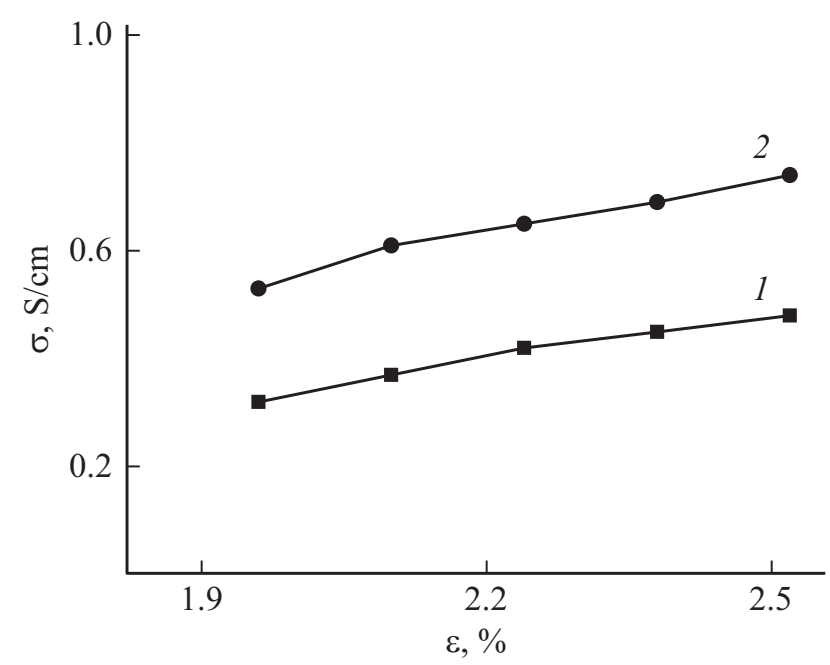

Рис. 4. Зависимость проводимости образцов ПВДФ/ПАНИ от степени „холодной“ вытяжки: однократная (1) и двукратная (2) полимеризация. (экструзия при $\lambda=55$ ). 


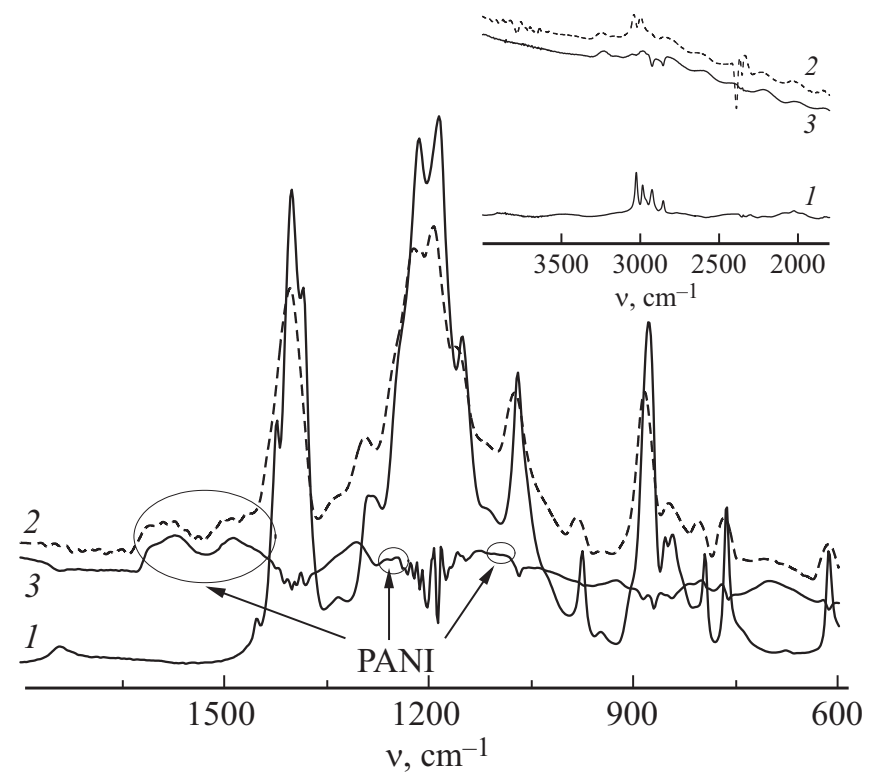

Рис. 5. ИК-спектры пористых пленок ПВДФ (1), образцов ПВДФ/ПАНИ (2) и разностный спектр (3); врезка вверху плато проводимости на спектре образца ПВДФ/ПАНИ (2) и на разностном спектре (3).

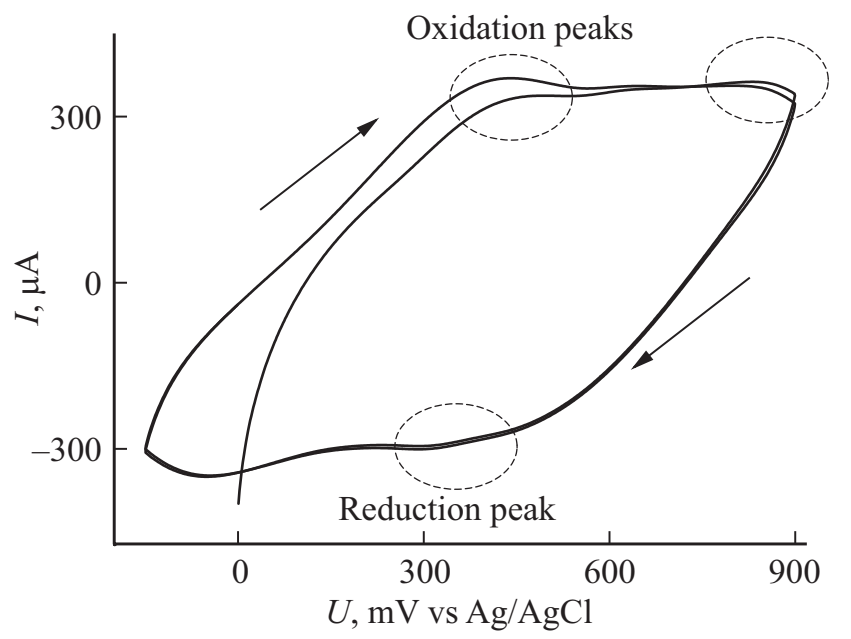

Рис. 6. Кривые циклической вольтамперметрии для образца ПВДФ/ПАНИ.

образом, эти данные подтверждают, что в гибридной системе ПАНИ/ПВДФ присутствует протонированная проводящая форма ПАНИ. На отдельной вставке на рис. 5 хорошо видно на спектре ПВДФ/ПАНИ так называемое „плато проводимости“ - участок спектра, на котором проводящая форма ПАНИ демонстрирует слабый наклон, который отсутствует в спектре ПВДФ, что является дополнительным подтверждением образования проводящего ПАНИ на пленках ПВДФ.

Важным результатом модификации пленок ПВДФ слоем ПАНИ является заметное повышение гидрофильности поверхности образцов, что подтверждается измерениями краевого угла методом сидячей капли: при смачивании водой он для пленки ПВДФ составляет $64^{\circ}$, для ПВДФ/ПАНИ - 76 .

Электроактивность систем ПАНИ/ПВДФ исследовали методом циклической вольтамперометрии. Измерения проводили в трехэлектродной ячейке в $1 \mathrm{M}$ растворе соляной кислоты. Пленка ПАНИ/ПВДФ служила рабочим электродом, в качестве токового электрода использовали платиновый электрод, электродом сравнения был хлорсеребряный электрод. На кривых циклической вольтамперометрии наблюдаются пики, соответствующие редокс-переходам в ПАНИ - пикам окисления (400 и $800 \mathrm{mV}$ : лейкоэмеральдин-эмеральдин и эмеральдинпернигранилин, соответственно) и соответствующим пикам восстановления $(300$ и $-50 \mathrm{mV})$ (рис. 6). Присутствие этих пиков свидетельствует о том, что ПАНИ сохраняет свою электроактивность в полученных образцах ПАНИ/ПВДФ и способен изменять свою степень окисления под действием электрического поля.

Исследование механических свойств образцов ПАНИ/ПВДФ показало, что введение жесткоцепного ПАНИ приводит к улучшению всех механических характеристик по сравнению с их значениями для подложки, а именно, наблюдается не только увеличение разрывного напряжения и модуля упругости, но и удлинения при разрыве (табл. 3). Увеличение деформируемости при одновременном возрастании модуля упругости является неожиданным результатом, поскольку, как правило, введение жесткоцепного полимера в композиционную систему приводит к снижению эластичности и, соответственно, уменьшению удлинения при разрыве. Можно предположить, что ПАНИ заполняет структурные дефекты исходной пленки ПВДФ, таким образом, упрочняя ее без ухудшения эластичности. Отметим, что для всех образцов наблюдалась высокая адгезия слоя ПАНИ к подложке, причем отслаивания проводящего покрытия не происходило даже при разрыве образца, что связано не только с рельефным характером поверхности пленок ПВДФ, но и с наличием слоя ПАНИ на стенках открытых к поверхности пор. Поскольку компоненты системы не связаны с какого-либо рода взаимодействиями, то их сцепление между собой осуществляется

Таблица 3. Механические свойства пористых пленок ПВДФ и образцов ПАНИ/ПВДФ

\begin{tabular}{c|c|c|c}
\hline $\begin{array}{c}\text { Кратность } \\
\text { фильерной } \\
\text { вытяжки }\end{array}$ & $\begin{array}{c}\text { Прочность, } \\
\text { МРа }\end{array}$ & $\begin{array}{c}\text { Модуль } \\
\text { упругости, } \\
\text { МРа }\end{array}$ & $\begin{array}{c}\text { Удлинение } \\
\text { при разрыве, \% }\end{array}$ \\
\hline$\lambda=55$ & $123 / 125$ & $720 / 810$ & $50 / 57$ \\
$\lambda=73$ & $137 / 140$ & $650 / 720$ & $44 / 50$ \\
$\lambda=103$ & $145 / 150$ & $600 / 670$ & $33 / 45$
\end{tabular}

Примечание. В числителе для пористых пленок ПВДФ, в знаменателе - для гибридных систем ПАНИ/ПВДФ (двойная полимеризация). 
Таблица 4. Пьезоэлектрические свойства образцов ПВДФ/ПАНИ

\begin{tabular}{c|c|c|c}
\hline $\begin{array}{c}\text { Суммарная } \\
\text { степень } \\
\text { вытяжки }\end{array}$ & $\begin{array}{c}\text { Содержание } \\
\beta \text {-фазы, \% }\end{array}$ & $\begin{array}{c}\text { Пьезомодуль } \\
d_{31}, \mathrm{pC} / \mathrm{N}\end{array}$ & $\begin{array}{c}\text { Пьезомодуль } \\
d_{32}, \mathrm{pC} / \mathrm{N}\end{array}$ \\
\hline 2.0 & 38 & 8 & $<2$ \\
2.1 & 40 & 10 & $<2$ \\
2.2 & 43 & 12 & 2.4
\end{tabular}

по механизму механической адгезии, характерной для контакта покрытия с рельефной подложкой.

Пористые пленки ПВДФ, полученные используемым в данной работе методом, обладают полиморфной кристаллической структурой с высоким содержанием пьезоактивной $\beta$-формы [11]. Пьезоэлектрические свойства образцов характеризовали величиной пьезомодуля $d_{i j}$ в режиме растяжения при приложении механического напряжения, не выходящего за пределы упругой деформации (не превышающее предел текучести). При приложении нагрузки наблюдали появление разности потенциалов на электродах, что свидетельствовало о том, что образец пьезоактивен.

В работе [11] было установлено, что при увеличении степени одноосного растяжения в процессе порообразования возрастает содержание пьезоактивной $\beta$-фазы в пленках ПВДФ. Исследования пьезоэлектрических свойств показали, что повышение степени ориентации при растяжении приводит также к непрерывному росту пьезомодуля (табл. 4).

В качестве электродных материалов использовали алюминиевую фольгу, эвтектический сплав галлийолово и слои электропроводящего ПАНИ, которые служили электродами как при определении пьезомодуля, так и при проведении поляризации образцов. Измерения проницаемости пленок ПВДФ до и после поляризации (с использованием алюминиевой фольги, которая затем удаляется) показали, что поляризация не оказывает влияния на их пористую структуру.

Ориентационные воздействия в процессе получения пленок на стадиях экструзии и одноосного растяжения приводят к тому, что структура микропористых образцов ПВДФ имеет анизотропный характер. Картины СЭМ (рис. 1) демонстрируют наличие анизотропных кристаллических образований, а также пор в форме эллипсов, расположенных между ламелями и имеющих ориентацию, соответствующую ориентации ламелей: молекулярные цепи в ламелях и соединяющие ламели тяжи вытянуты в направлении ориентации образца. Были определены значения пьезоконстант в зависимости от направления приложения растягивающей нагрузки при его измерении. Результаты показали, что при приложении нагрузки вдоль направления ориентации (модуль $d_{31}$ ) наблюдается более высокий пьезомодуль, максимальное значение которого составляет $12 \mathrm{pC} / \mathrm{N}$, в то время как в перпендикулярном направлении (модуль $d_{32}$ ) оно равно $2.4 \mathrm{pC} / \mathrm{N}$, что является следствием ориентированного характера структуры образцов (табл. 4).

При измерении пьезохарактеристик гибридных пленок ПВДФ/ПАНИ было установлено, что значения пьезомодуля $d_{31}$ для этих образцов совпадают с величинами, полученными для пленок ПВДФ с помощью металлических электродов, что свидетельствует о корректности использования проводящих полимеров в качестве электродного материала.

\section{4. Заключение}

Получены гибридные пьезоактивные полимерные системы методом формирования на поверхности микропористых пьезопленок ПВДФ слоев электропроводящего полимера (ПАНИ) с использованием нового подхода - повторной полимеризации проводящего компонента, который позволил достичь высокой однородности и упорядоченности слоя ПАНИ и существенно повысить его электропроводность. Исследования образцов ПВДФ/ПАНИ методами электронной микроскопии и ИК-спектроскопии показали, что слои ПАНИ образованы полианилином в его проводящей форме - эмеральдиновой соли. Важным фактором является высокая адгезия слоя к подложке, связанная с рельефным характером поверхности пористых пленок ПВДФ и их пористой структурой, что обеспечивает целостность материала при механической нагрузке. Измерения механических характеристик показали, что полученные образцы ПВДФ/ПАНИ обладают более высокими разрывной прочностью и модулем упругости, чем подложки, и при этом показывают и большую эластичность (более высокое удлинение при разрыве). Благодаря высокому содержанию пьезоактивной кристаллической формы в пористых подложках ПВДФ и разработанному методу эффективной высоковольтной поляризации, полученные гибридные системы ПВДФ/ПАНИ обладают высоким пьезомодулем, а структурно-физические характеристики проводящих слоев ПАНИ позволили использовать их в качестве контактных электродов при поляризации пленок и измерении пьезомодуля. С помощью разработанного подхода сформирован готовый к применению полностью полимерный гибридный материал для использования в качестве пьезоэлемента (пьезодатчика) любого размера и формы. Этот результат достигается последовательным применением методик, которые могут быть объединены в непрерывный технологический процесс. Сочетание пьезоэлектрических характеристик ПВДФ и уникальных электрохимических свойств электропроводящих полимеров делает полученные гибридные материалы перспективными для использования в разного рода системах накопления и запасания энергии (пьезоактиваторов, пьезосуперконденсаторов, пьезобиосенсоров и т.д.). 


\section{Благодарности}

Авторы выражают благодарность Е.Н. Власовой за получение ИК-спектров ПВДФ и ПВДФ/ПАНИ.

\section{Конфликт интересов}

Авторы заявляют, что у них нет конфликта интересов.

\section{Список литературы}

[1] Y. Bar-Cohen, Q. Zhang. MRS Bulletin 33, 173 (2008).

[2] A.J. Lovinger. Science 220, 1115 (1983).

[3] E. Fukada. IEEE Transact. Ultrasonics, Ferroelectrics Frequency Control 47, 1277 (2000).

[4] A. Salimi, A.A. Yousefi. Polymer Testing 22, 699 (2003).

[5] Y.M. Chang, J.S. Lee, K.J. Kim. Solid State Phenomena 124, 299 (2007).

[6] P. Martins, A.C. Lopes, S. Lanceros-Mendez. Prog. in Polymer Sci. 39, 683 (2014).

[7] В.В. Кочервинский. Успехи химии 65, 936 (1996).

[8] И.Ю. Дмитриев, В.К. Лаврентьев, Г.К. Ельяшевич. Высокомоляр. соединения 48 А, 447 (2006).

[9] И.Ю. Дмитриев, И.С. Курындин, В.К. Лаврентьев, Г.К. Ельяшевич. ФТТ 59, 1013 (2017).

[10] И.Ю. Дмитриев, И.С. Курындин, Г.К. Ельяшевич. Патент РФ № 2635804 (2017).

[11] G.K. Elyashevich, I.S. Kuryndin, I.Yu. Dmitriev, V.K. Lavrentyev, N.N. Saprykina, V. Bukošek. Chin. J. Polymer Sci. 37, 1283 (2019). DOI: 10.1007/s10118-019-2284-2

[12] D. Stauffer, A. Aharony. Introduction to percolation theory. Taylor and Francis, London (1994). 192 p.

[13] Г.К. Ельяшевич, Е.Ю. Розова, Е.А. Карпов. Патент РФ № 2140936 (1997).

[14] И.С. Курындин, В.К. Лаврентьев, V. Bukošek, Г.К. Ельяшевич. Высокомоляр. соединения 57 А, 497 (2015).

[15] А. Stolarczyk, Г.К. Ельяшевич, Е.Ю. Розова, M. Lapkowski. Высокомоляр. соединения. 47 А, 524 (2005).

[16] A.L. Buyanov, L.G. Revel'skaya, E.Yu. Rosova, G.K. Elyashevich. J. Appl. Pol. Sci. 94, 1461 (2004).

[17] G.K. Elyashevich, E.Yu. Rosova, D.V. Andreeva, G.A. Polotskaya, M. Trhova, Z. Pientka. J. Appl. Pol. Sci. 97, 1410 (2005).

[18] A. Bobrovskii, V.P. Shibaev, G.K. Elyashevich, E.Yu. Rosova, A. Shimkin, V. Shirinyan, K.-L. Cheng. Polymers Adv. Technol. 21, 100 (2010).

[19] Г.К. Ельяшевич, М.А. Смирнов. Высокомоляр. соединения $54 \mathrm{~A}, 1675$ (2012).

[20] G.K. Elyashevich, I.S. Kuryndin, E.Yu. Rosova. Polymers Adv. Technol. 13, 725 (2002).

[21] M. Liu, J. Li, Z. Guo. J. Colloid Interface Sci. 467, 261 (2016).

[22] Y. Fu, H. He, T. Zhao, Y. Dai, W. Han, J. Ma, L. Xing, Y. Zhang, X. Xue. Nano-Micro Lett. 10, 76 (2018). https://doi.org/10.1007/s40820-018-0228-y

[23] C.S. Lee, J. Joo, S. Han, J.H. Lee, S.K. Koh. J. Korean Phys. Soc. 45, 747 (2004).

[24] R. Minato, G. Alıcı, S. McGovern, G. Spinks. Proc. SPIE 6524, 65241J, (2007).

[25] S.P. Ozkorucuklu, K. Özdemir, E. Kır. Polymers Adv. Technol. 23, 1202 (2012).
[26] C. Merlini, G.M.O. Barra, T.M. Araujo, A. Pegoretti. RSC Adv. 4, 15749 (2014). DOI: 10.1039/c4ra01058b

[27] L.F. Malmonge, G. de A. Lopes, S. de C. Langiano, J.A. Malmonge, J.M.M. Cordeiro, L.H.C. Mattoso. Eur. Polymer J. 42, 3108 (2006).

[28] S. Ray, A.J. Easteal, R.P. Cooney, N.R. Edmonds. Mater. Chem. Phys. 113, 829 (2009).

[29] Е.Ю. Розова, И.С. Курындин, Н.В. Боброва, Г.К. Ельяшевич. Высокомоляр. соединения 46 Б, 923 (2004).

[30] M. Blaha, M. Trchova, P. Bober, Z. Moravkova, J. Prokes, J. Stejskal. Mater. Chem. Phys. 194, 206 (2017).

Редактор К.В. Емцев 